\title{
Analysis of dynamic behavior of the back-to- back High Voltage Direct Current link model as part of electrical power system
}

\author{
Vladimir Rudnik ${ }^{1, *}$, Nikita Desyukov ${ }^{1}$, and Ruslan $\mathrm{Ufa}^{1}$ \\ ${ }^{1}$ National Research Tomsk Polytechnic University, 634050 Tomsk, Russia
}

\begin{abstract}
One of the main directions of the development of electric power systems is the introduction of technologies based on high-power semiconductor switches, such as FACTS devices and HVDC technologies. These systems effectively solve a number of urgent tasks of EPS, connected with asynchronous connection of EPS, transmission of electricity, improve local and systemic flexibility and reliability of EPS, increasing the capacity of network elements that contains a "weak" connection. However, the implementation and operation of mentioned technologies in the EPS determines the need for a wide range of analysis and research that can only be done with the help of mathematical modeling.
\end{abstract}

\section{Introduction}

One of the main directions of development of electric power systems (EPS) is the introduction of devices and technologies based on power semiconductor switches (FACTS devices and HVDC technologies), which are designed to improve flexibility, network capacity and ensure the reliability of electricity transmission $[1,2]$. B2B HVDC link is a converter station that used to convert alternative current (AC) to direct current (DC) and then convert DC to AC the same or other frequency. B2B HVDC link solves the following tasks: asynchronous connection of EPS; increasing of local and system flexibility and reliability of EPS; increasing of transmission line capacity. Number of research and analysis of B2B HVDC link operation should be done, before introduction in the EPS [2-4].

\section{B2B HVDC link model}

Properties and opportunities of B2B HVDC link will be analyzed via the B2B HVDC link model realized in the Matlab Simulink and the Hybrid Real Time Simulator (HRTSim) [59].

\footnotetext{
* Corresponding author: fordlp006@mail.ru
} 


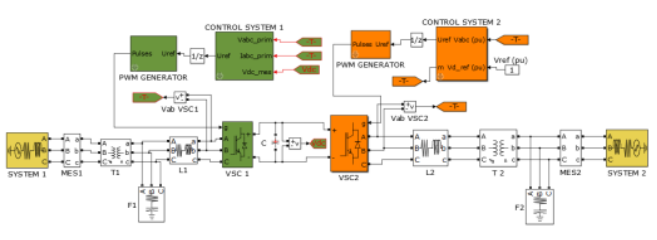

a)

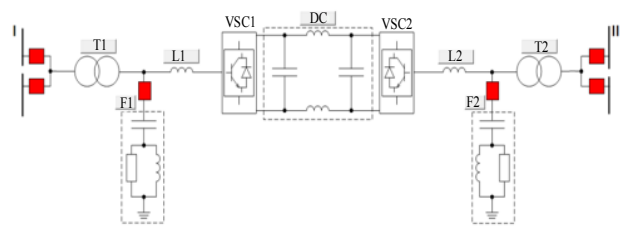

b)

Fig. 1. The B2B HVDC link model realized in the Matlab Simulink (a) and HRTSim (b) where $T 1,2$ - transformer, $L$ 1,2 - reactor, DC - direct current link, VSC 1,2 - voltage source converter, PWM pulse-width modulation, F 1,2 - harmonic filter.

According to the $[10,11]$ the following scenarios should carry out to confirm the benefits of B2B HVDC link: asynchronous connection of the EPS; short circuit on one side of the EPS; step change and reverse of transmitted power.

\subsection{Asynchronous connection of EPS}

In Fig. 2 the oscillograms of voltage and currents on the side of the System 1 and System 2, and the voltage in the DC circuit, after the connection of the two power systems, are presented.

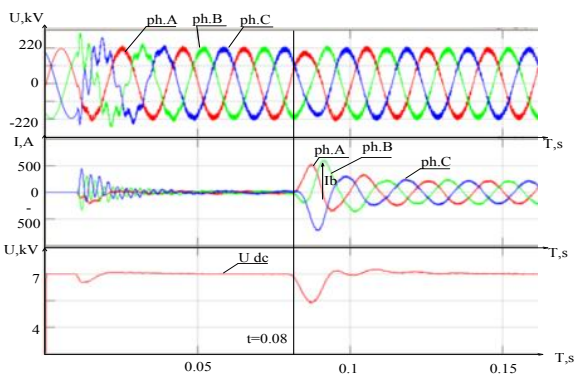

a)

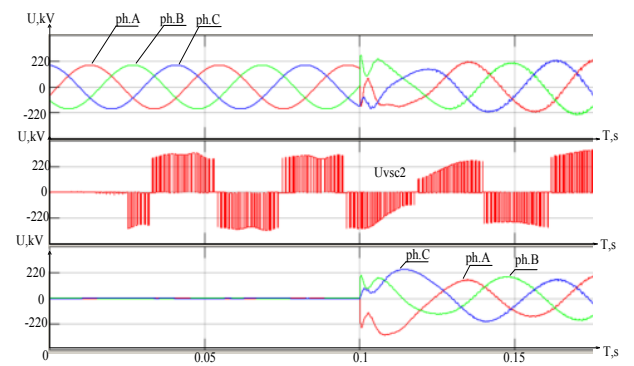

b)

Fig. 2. Oscillograms of the voltage in the DC circuit, voltages and currents on the System 1 (a) and and System 2 (b).

According to the oscillograms shown in Figure 3, the voltage of phase A on the side the System 1 and System 2 after the connection of the two power systems $(0.08 \mathrm{~s}$. $)$ the same frequency is observed in both power systems. This confirms the correct functioning of the B2B HVDC link, however a higher harmonics, which are generated by VSC, is occurred. To eliminate the higher harmonics possible with the correct tuning of the higher-order harmonic filter.

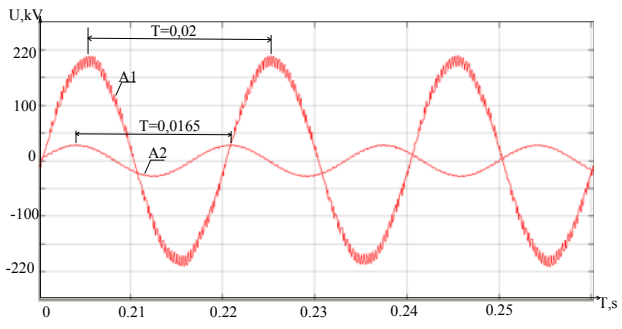

Fig. 3. Oscillograms voltage of the phase A on the side the EPS 1 and the EPS 2 after the connection of the two power systems. 


\subsection{Short circuit on side the EPS 2}

At the initial time of the EPS 1 transmits power to the EPS 2, then, at the $0.1 \mathrm{~s}$. there is a short circuit on the side of the power system 2. Figure 4a shows oscillograms of voltages and currents of power systems using a power line.

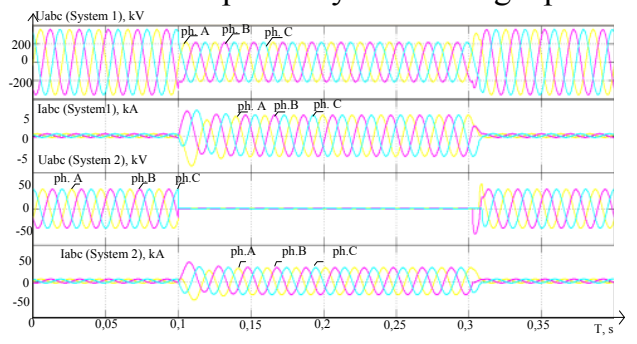

a)

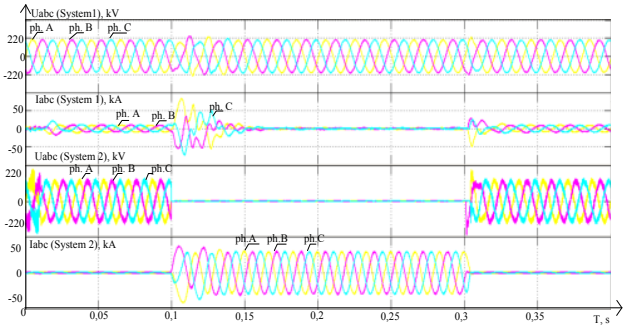

b)

Fig. 4. Oscillograms of currents and voltages under AC short circuit without (a) and with (b) B2B HVDC link realized in the Matlab Simulink.

According to the oscillograms shown in Fig. 4b, when there is a short circuit on the side of the EPS 2, there is an increase in the currents of the two power systems

When power systems are connected with the B2B HVDC link implemented in the Matlab Simulink (Fig. 4b), it is seen that in the time interval 0.1-0.2 s. There was a sharp jump in currents of up to $30 \mathrm{kA}$, as well as a drawdown of voltages on the side of the EPS 2, while the currents and voltages of the EPS 1 remained practically unchanged.

When connecting the EPS with the HVDC implemented in the HRTSim (Fig. 5), the following scenario. At time 0,5, a three-phase earth fault occurs on the side of the power system 1 , then within $0.1 \mathrm{~s}$. the relay protection system disconnects the EPS 1 and at the instant 0,19 the automatic restart of the System 1 is triggered. Fig. 5 shows that during the short-circuit the System 2 operates in normal mode.

The results of the research show that with the use of the B2B HVDC link it is possible to make a complete decoupling of the power systems, that is, an accident that occurred on one power system does not affect the operation of another power system.

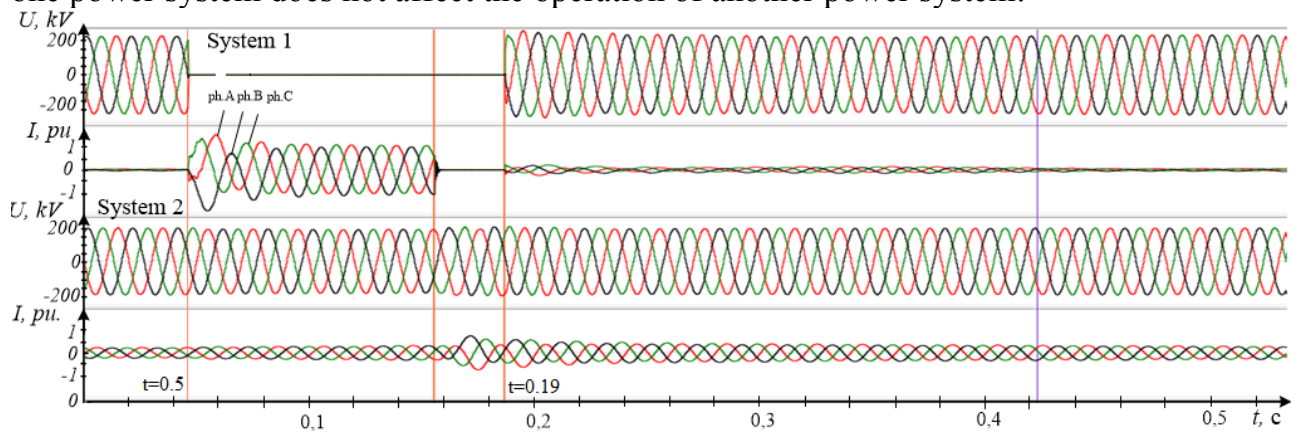

Fig. 5. Oscillograms of currents and voltages under AC short circuit with B2B HVDC link realized in the HRTSim.

\section{Conclusion}

As a result of the research, an analysis was made of the interaction of the B2B HVDC link with the adjacent power system. One of the ways to carry out such an analysis was modeling, which was carried out with of the Matlab Simulink and the HRTSim. Three situations were considered in connection two asynchronous operating power systems: 
frequency differences 50 and $60 \mathrm{~Hz}$; the appearance of a fault; step change and reverse of transmitted power of the B2B HVDC link. The analysis showed that it is possible to connection two asynchronous operating power systems without any failure situations. It is also worth noting that when performing research using the Matlab Simulink and the HRTSim, there is a general trend in the results. This suggests that the HRTSim correctly performs simulation.

This work was supported by the Non-profit Partnership "Global Energy' under the project No. MG- 2017/04/1 "Developing a hardware and software platform for all-regimes real-time simulation of intelligent electric power systems".

\section{References}

1. K. Vijay, Sud. HVDC and Controllers: applications of static converters in power systems (2009)

2. R.L. Sellick, M. Åkerberg, 10th IET Int. Conf. AC DC Power Transmission. Birmingham (2012)

3. A. Suvorov, Y. Borovikov, A. Gusev, A. Sulaymanov, M. Andreev, N. Ruban, R. Ufa, Electrical eng. 99 (2017), DOI: 10.1007/s00202-016-0464-4

4. Yu. Borovikov, A. Prokhorov, M. Andreev, 7th Int. Forum Strategic Techol. 2 (2012), 10.1109/IFOST.2012.6357823

5. M. Andreev, A. Sulaymanov, A. Suvorov, MATEC Web Conf. 37 (2015), DOI: 10.1051/matecconf/20153701001

6. A.A. Suvorov, A.S. Gusev, A.O. Sulaymanov, O.V. Suslova, MATEC Web Conf. 91 (2016), DOI: 10.1051/matecconf/20179101052

7. N.Y. Ruban, Y.S. Borovikov, A.O. Sulaymanov, A.S. Gusev, IFOST (2016), DOI: 10.1109/IFOST.2016.7884255

8. N.Yu. Ruban, A.S. Gusev, A.Yu. Pishchulin, MATEC Web Conf. 37 (2015), DOI: $10.1051 /$ matecconf $/ 20153701046$

9. A. Gusev, A. Suvorov, A. Sulaymanov, MATEC Web Conf. 37 (2015), DOI: 10.1051/matecconf/20153701023

10. M. Khatir, S. Ahmed Zidi, S.Hadjeri, J. Electrical Eng. 61, 1 (2010)

11. Xu Lie, B.R. Andersen, P. Cartwright, Transmission Distribution Conf. Exposition, IEEE PES, 2 (2003) 